Revista Eletrônica de Direito Processual - REDP.

Rio de Janeiro. Ano 15. Volume 22. Número 2. Maio a Agosto de 2021

Periódico Quadrimestral da Pós-Graduação Stricto Sensu em Direito Processual da UERJ

Patrono: José Carlos Barbosa Moreira (in mem.). ISSN 1982-7636. pp. 166-186 www.redp.uerj.br

\title{
DA SUPERAÇÃO DA INDISPONIBILIDADE DO OBJETO LITIGIOSO E IMPORTÂNCIA SOBRE A ANÁLISE COM BASE EM CRITÉRIOS DE ECONOMICIDADE E EFICIÊNCIA PARA A ESCOLHA DO ADEQUADO MEIO DE RESOLUÇÃO DE CONFLITOS PELA ADMINISTRAÇÃO PÚBLICA ${ }^{1}$
}

\author{
OVERCOMING THE UNAVAILABILITY OF THE OBJECT IN DISPUTE AND THE \\ IMPORTANCE OF ANALYSIS BASED ON CRITERIA OF ECONOMY AND \\ EFFICIENCY FOR THE CHOICE OF THE APPROPRIATE MEANS OF \\ CONFLICT RESOLUTION BY THE PUBLIC ADMINISTRATION
}

Cristiane Rodrigues Iwakura Doutora e Mestre em Direito Processual pela Universidade do Estado do Rio de Janeiro - UERJ. Pós-Graduada em Direito Público pela Universidade de Brasília - UnB e em Regulação do Mercado de Capitais pelo Ibmec-RJ. Instrutora de Direito Processual Civil e Coordenadora de Disciplinas na PósGraduação e no Mestrado Profissional em Advocacia Pública da Escola da Advocacia Geral da União. Rio de Janeiro/RJ. Email: crisiwakura@yahoo.com.br.

RESUMO: Este artigo tem por objetivo promover uma releitura do interesse público disponível, tomando-se por base várias premissas e conceitos desenvolvidos pela doutrina processualista e administrativista ao longo destes últimos anos, de modo que se possa desvendar quais seriam os casos em que a Administração Pública poderá eleger um mecanismo alternativo para a resolução de conflitos, e, dentre as espécies existentes, com destaque para a arbitragem e a mediação, como deve avaliar o melhor método a ser utilizado, a partir de uma análise com base em critérios de economicidade e de eficiência, em consonância com os princípios constitucionalmente estabelecidos.

\footnotetext{
${ }^{1}$ Artigo recebido em 28/11/2020 e aprovado em 14/04/2021.
} 
Revista Eletrônica de Direito Processual - REDP.

Rio de Janeiro. Ano 15. Volume 22. Número 2. Maio a Agosto de 2021

Periódico Quadrimestral da Pós-Graduação Stricto Sensu em Direito Processual da UERJ

Patrono: José Carlos Barbosa Moreira (in mem.). ISSN 1982-7636. pp. 166-186

www.redp.uerj.br

PALAVRAS-CHAVE: Disponibilidade do objeto litigioso. Meios alternativos de solução de conflitos. Mediação. Arbitragem. Administração Pública. Economicidade. Eficiência.

ABSTRACT: This article aims to promote a rereading of the available public interest, based on several premises and concepts developed by the procedural and administrative doctrine over the past few years, so that it is possible to discover which are the cases in which the Public Administration may elect an alternative mechanism for the resolution of conflicts, and, among the existing species, with emphasis on arbitration and mediation, how should evaluate the best method to be used, based on an analysis based on criteria of economy and efficiency, in line with the constitutionally established principles.

KEYWORDS: Availability of the disputed object. Alternative means of conflict resolution. Mediation. Arbitration. Public administration. Economics. Efficiency.

\section{INTRODUÇÃO}

Já faz um bom tempo que os mecanismos alternativos vêm sendo amplamente utilizados para a solução de conflitos envolvendo a Administração Pública.

Vale relembrar que ainda na vigência do CPC de 1973 colocava-se a indisponibilidade do objeto litigioso como barreira intransponível para a negociação entre particulares e Fazenda Pública.

Em sede judicial, enunciava o art. 447 do antigo Código Processual Civil que somente em litígios versando sobre direitos patrimoniais de caráter privado, o juiz, de ofício, determinaria o comparecimento das partes ao início da audiência de instrução e julgamento para tentar estabelecer uma conciliação.

A partir desta redação, a interpretação do dispositivo orientava os magistrados no sentido de que a conciliação não tinha lugar quando se estivesse simplesmente diante de uma ação em face da Fazenda Pública.

O impacto da exegese extraída da norma em questão era tão grande, que os servidores cartorários ao identificarem na capa do processo a presença da Fazenda Pública, lançavam automaticamente um despacho com texto padronizado indicando a inviabilidade de 
Revista Eletrônica de Direito Processual - REDP.

Rio de Janeiro. Ano 15. Volume 22. Número 2. Maio a Agosto de 2021

Periódico Quadrimestral da Pós-Graduação Stricto Sensu em Direito Processual da UERJ

Patrono: José Carlos Barbosa Moreira (in mem.). ISSN 1982-7636. pp. 166-186

www.redp.uerj.br

transação, portanto, dispensando as partes de comparecerem à audiência prévia de conciliação referida no art. 331 do CPC/73.

No art. 331 em destaque o legislador mencionava como condição para a audiência de conciliação a disponibilidade do objeto litigioso, que no caso da Fazenda Pública era considerada a partir de uma interpretação sobre o arts. 100 e 102 do Código Civil de 2002 que reputavam esses bens como inalienáveis e irrenunciáveis, via de regra ${ }^{2}$.

Ora, resta mais do que evidente a construção simplista de causa e efeito que ali se propunha: o Código Civil conferia aos bens públicos de uso comuns do povo e de uso especial o atributo da inalienabilidade, logo, eram todos indisponíveis, portanto, não transacionáveis na forma do art. 331 e 447 do CPC/73.

A generalização de indisponibilidade dos bens públicos a partir das mencionadas normas civis era algo claramente equivocado, já que o comando legal excepcionava os bens dominicais deste tratamento, assim como também qualquer bem público que se desvinculasse de sua destinação originalmente tutelada como inalienável.

Consequentemente, a generalização indevida foi sendo estendida para outros institutos, na medida em que a inalienabilidade dos bens públicos passou a constituir uma premissa quase absoluta, o que deu origem a uma outra afirmação desacertada no sentido de que a Fazenda Pública jamais sofreria os efeitos da revelia (art. 320 do CPC/73).

Felizmente, com o passar do tempo, a prática reiterada conduzida sob esta ótica encarregou-se de naturalmente demonstrar que certos dogmas e cânones não possuíam razão para permanecer no cenário jurídico.

A realidade dos fatos apresenta-se como um catalisador orgânico: da mesma forma que o corpo humano, qualquer elemento estranho que não se demonstre em harmonia com o restante começa a provocar reações indesejadas, forçando o sistema a promover a sua remoção ou expulsão, tendo por objetivo a manutenção de sua higidez.

Assim, reativamente, observou-se um progressivo descompasso do movimento conciliatório com aquele obstáculo de cunho meramente patrimonial e pseudo-protecionista

\footnotetext{
${ }^{2}$ Via de regra, pois os atributos da inalienabilidade e consequente indisponibilidade são conferidos aos bens comuns e de uso especial, estando os dominicais ou que se desviem da destinação referida no art. 100 do Código Civil expressamente excepcionados.
} 
Revista Eletrônica de Direito Processual - REDP.

Rio de Janeiro. Ano 15. Volume 22. Número 2. Maio a Agosto de 2021

Periódico Quadrimestral da Pós-Graduação Stricto Sensu em Direito Processual da UERJ

Patrono: José Carlos Barbosa Moreira (in mem.). ISSN 1982-7636. pp. 166-186

www.redp.uerj.br

que vinha desde há um bom tempo impedindo o Poder Público de transacionar com os seus administrados.

Uma das constatações mais marcantes era a falta de coerência. A norma que pretensamente tornava o bem público inalienável tinha por objetivo garantir uma maior segurança ao erário fazendário. Mas como garantir essa segurança de cunho patrimonialista, quando a conciliação poderia permitir efetivamente uma solução mais rápida e economicamente mais vantajosa ao ente público?

Ademais, as exceções previstas no texto do Código Civil ao se referirem aos bens públicos dominicais ou desvirtuados de sua finalidade original persecutória do interesse público nunca se harmonizaram com o comando impeditivo para o uso de meios alternativos a todas as causas envolvendo a Fazenda Pública, indistintamente.

A partir de então, doutrina e jurisprudência passaram a rever este entendimento inicial, fazendo uma distinção dos interesses públicos como primários e secundários, exatamente para esclarecer a razão das normas descritas nos artigos 100 e 102 do Código Civil, com respectivos desdobramentos.

Definindo-se com maior exatidão o que se entenderia por interesse público primário, restou claro que os interesses públicos secundários poderiam ser objeto de transação.

Em sequência, a Lei $\mathrm{n}^{\circ}$ 9.307/96 consagrou a possibilidade de se utilizar a arbitragem nas causas envolvendo a Fazenda Pública eliminado qualquer dúvida residual quanto à possibilidade de utilização de um meio alternativo.

Da mesma forma, com o advento do CPC de 2015, que reforçou ainda mais a utilização dos meios alternativos, ainda mais por se tratar de um excelente filtro de demandas judiciais mediante a crise do Poder Judiciário latente na época em que entrou em vigor, a Administração Pública passou a intensificar, internamente, a regulação de atos por meio de atos normativos, envolvendo autorizações para a realização de acordos entre entes públicos e do Poder Público com particulares.

Essa normatização interna buscou exatamente conferir ao agente público maior segurança jurídica para adotar os mecanismos alternativos de solução de controvérsias eliminando aparentes antinomias decorrentes das prerrogativas fazendárias, a exemplo do que se constatou na Lei $n^{\circ}$ 9.307/96 (Lei de Arbitragem). 
Revista Eletrônica de Direito Processual - REDP.

Rio de Janeiro. Ano 15. Volume 22. Número 2. Maio a Agosto de 2021

Periódico Quadrimestral da Pós-Graduação Stricto Sensu em Direito Processual da UERJ

Patrono: José Carlos Barbosa Moreira (in mem.). ISSN 1982-7636. pp. 166-186

www.redp.uerj.br

\section{DEFINIÇÃO DO INTERESSE PÚBLICO DISPONÍVEL COMO ETAPA PRELIMINAR À UTILIZAÇÃO DOS MEIOS ALTERNATIVOS}

Em conceitos abertos, a definição por exclusão demonstra-se mais adequada, na medida em que se demonstra impossível enumerar taxativamente todas as possíveis hipóteses de enquadramento.

Para a identificação do interesse público disponível revela-se interessante e oportuna a concepção de um método trifásico, sendo este consistente na verificação de vários aspectos e circunstâncias sobre um bem da vida de titularidade do Poder Público em três etapas ${ }^{3}$.

A primeira etapa consiste basicamente na diferenciação entre interesse público e interesse do Estado. Não raro, os conceitos de interesse público são confundidos com os interesses do governo, o que é inaceitável. Para Hélio do Valle Pereira, "o Estado são todos e não é ninguém". Esta frase ilustra muito bem a natureza do Estado a partir de uma concepção sociológica, pois ao mesmo tempo que se constrói a partir da reunião da vontade dos governados, outorgando-lhe poder para organizar e administrar os interesses envolvidos, não pode representar uma determinada fatia da sociedade, mas um verdadeiro amálgama de direitos e deveres que lhes foram conferidos a partir de um contrato social ao longo de um processo democrático ${ }^{4}$.

Logo, é importante se ter em mente que o Estado jamais deve ser confundido com o interesse público ${ }^{5}$. Da mesma forma, não há se cogitar em conflito do interesse público

\footnotetext{
3 IWAKURA, Cristiane Rodrigues. Conciliação na Administração Pública. Dissertação de mestrado apresentada e defendida em 2010 no Programa de Pós-graduação Stricto sensu da UERJ. Orientação: Professor Leonardo Greco. Disponível no site: http://dominiopublico.mec.gov.br/download/teste/arqs/cp148216.pdf. Acesso em: 11 fev. 2019, p. 72.

${ }^{4}$ PEREIRA, Hélio do Valle. Manual da Fazenda Pública em Juízo. 2 ed. Rio de Janeiro: Renovar, 2006, p. 37-41. O Estado, mesmo que dogmaticamente tenha configuração de pessoa jurídica, não pode ser assimilado com essa simplicidade, equiparando-se a um agrupamento contingencial de pessoas. Admite-se que seja vislumbrado o Estado como um ente jurídico, a exemplo de tantos outros, mormente de natureza privada, mas se trata de construção voltada à facilitação da aplicação de variados institutos jurídicos, presos aos conceitos de "personalidade". Não se cuida de construção que deva ser desprezada, mas é apenas uma faceta da questão. O Estado, realidade sociológica bem precedente às elucubrações doutrinárias, tem dimensão maior. Usandose chavão, o Estado são todos e não é ninguém. Não se deseja capitular as metáforas do "contrato social", mas não se pode perder de mira essa dimensão mais nobre, refratária a circunstâncias transitórias. Por extensão, não é viável desejar, por devoção à entidade imaterializada, o seu enaltecimento, exaltação que vale por si mesma, à revelia de valor superior.

${ }^{5}$ Ibidem, p. 41. Para Hélio do Valle Pereira, “o interesse público não se opõe ao Estado, mas também com ele não se confunde. O Estado, em verdade, é um vetor do interesse público; instituição que há de estar voltada
} 
Revista Eletrônica de Direito Processual - REDP.

Rio de Janeiro. Ano 15. Volume 22. Número 2. Maio a Agosto de 2021

Periódico Quadrimestral da Pós-Graduação Stricto Sensu em Direito Processual da UERJ

Patrono: José Carlos Barbosa Moreira (in mem.). ISSN 1982-7636. pp. 166-186

www.redp.uerj.br

com os interesses privados, que em grande parte não são antagônicos e tampouco desvinculados uns dos outros ${ }^{6}$.

A segunda etapa, por sua vez, relaciona-se com o conteúdo do interesse público, ou seja, os valores que devem ser respeitados e protegidos, hábeis a justificar um tratamento diferenciado, sempre com o objetivo de se conferir uma especial proteção ao direito concebido dentro da esfera publicista. $O$ interesse público representa um conjunto de interesses de um determinado grupo envolvido no caso concreto.

$\mathrm{Na}$ terceira etapa de identificação do interesse público, deve-se atentar à dimensão ética, representativa de uma significativa pluralidade social, especialmente comprometida com a realização do princípio da dignidade humana. A respeito disto, o Professor de Direito Administrativo Marçal Justen Filho destaca a personalização do fenômeno jurídico em detrimento da sua patrimonialização tendo por objetivo a satisfação dos valores fundamentais ${ }^{7}$.

Para o autor, um interesse deixa de ser privado quando não exista possibilidade de se transigir sobre ele, e mais: nem tudo que for indisponível será necessariamente um interesse público, mas certamente todo interesse verdadeiramente público deverá revestir-se de indisponibilidade ${ }^{8}$.

exclusivamente à sua consecução. Não está acima dele e nem é a sua síntese. É mecanismo subserviente do interesse público".

6 LEMES, Selma Ferreira. Arbitragem na administração pública: fundamentos jurídicos e eficiência econômica. São Paulo: Quartier Latin, 2007, p. 129. Destaca a autora que: "em acurado estudo sobre a boa-fé e a atuação da Administração Pública, o professor espanhol Jesús Gonzáles Pérez, ao analisar o caráter público de certos interesses, esclarece que estes não são antagônicos e não se encontram desvinculados dos interesses privados e que não existem interesses públicos" distintos dos que interessam particularmente aos cidadãos. Pondera ainda que "os interesses públicos e os interesses privados estão entrelaçados entre si até o ponto em que qualquer interesse público é também interesse privado".

7 JUSTEN FILHO, Marçal. Conceito de interesse público e a "Personalização" do Direito Administrativo. In Revista Trimestral de Direito Público. Vol. 26. São Paulo: Malheiros, 1999, p. 115-120.

${ }^{8}$ Ibidem, p. 122. Para o jurista, um interesse deixa de ser privado quando sua satisfação não possa ser objeto de alguma transigência. Recolocando o problema em outros termos, um interesse é público por ser indisponível e não o inverso. Por isso, é incorreto afirmar que algum interesse, por ser público, é indisponível. Esse modo de enfrentar o problema é incorreto, já que o interesse somente é qualificado como público por ser indisponível. Portanto, a indisponibilidade não é consequência da natureza pública do interesse œ é justamente o contrário. O interesse é reconhecido como público porque é indisponível, porque não pode ser colocado em risco, porque sua natureza exige que seja realizado. Como visto, existem interesses coletivos múltiplos, distintos, contrapostos œ todos eles merecendo tutela por parte do direito. Bem por isso, o critério da — supremacia do interesse público apresenta utilidade reduzida, uma vez que não há um interesse único a ser reputado como supremo. 
Revista Eletrônica de Direito Processual - REDP.

Rio de Janeiro. Ano 15. Volume 22. Número 2. Maio a Agosto de 2021

Periódico Quadrimestral da Pós-Graduação Stricto Sensu em Direito Processual da UERJ

Patrono: José Carlos Barbosa Moreira (in mem.). ISSN 1982-7636. pp. 166-186

www.redp.uerj.br

Dalmo de Abreu Dallari, na mesma linha, utiliza-se do critério da dimensão ética incorporando à definição de interesse público um elemento excludente de atos que se demonstrem ilegítimos e antiéticos ainda que emanados pela Administração Pública ${ }^{9}$.

A relação do interesse público com a realização dos direitos fundamentais constitucionalmente estatuídos, bem como com a proteção da dignidade da pessoa humana, traz à tona a relevância de sua exata identificação para o exercício da atividade administrativa, servindo-se como elemento norteador e balizador da conduta dos administrados, como fator decisivo para a ponderação dos bens juridicamente envolvidos em cada situação apresentada, e como fundamentação para a tomada de decisões por parte dos agentes públicos.

A identificação da presença de um interesse público primário em sua essência invoca uma especial proteção sobre os direitos e bens envolvidos, sejam eles pertencentes ao Poder Público ou particulares, de modo que se torne viável a ampla utilização de meios alternativos ao lado de outras medidas importantes para a desjudicialização dos conflitos existentes. $^{10}$

Selma Ferreira Lemes destaca a existência de duas funções para o interesse público sob o prisma da eficiência econômica: A primeira, seria proporcionar a realização do bem comum, atentando-se para a proteção dos interesses dos administrados e ao melhor cumprimento dos fins da administração (tal como preconizado na Lei $n^{\circ}$ 9.784/99 que rege os processos administrativos na esfera federal $)^{11}$.

\footnotetext{
${ }^{9}$ DALLARI, Dalmo de Abreu. Elementos de teoria geral do Estado. São Paulo: Saraiva, 2002, p. 47. Não há interesse público legítimo ao se procrastinarem pagamentos efetivamente devidos, pois o interesse público está na correta aplicação da lei, de acordo com a melhor interpretação possível diante do caso concreto, em benefício da coletividade, dos cidadãos integrantes da coletividade. Nas palavras do jurista, "a própria natureza dos fins do Estado exige dele uma ação intensa e profunda, continuamente desenvolvida, para que ele possa realizá-los, o que produz, inevitavelmente, uma permanente possibilidade de conflitos de interesses, que serão resguardados e adequadamente promovidos só através do direito. E por meio da noção do Estado como pessoa jurídica, existindo na ordem jurídica e procurando atuar segundo o direito, que se estabelecem limites jurídicos eficazes à ação do Estado, no seu relacionamento com os cidadãos. Se, de um lado, é inevitável que o Estado se torne titular de direitos que ele próprio cria por meio de seus órgãos, há, de outro, a possibilidade de que os cidadãos possam fazer valer contra ele suas pretensões jurídicas, o que só é concebível numa relação entre pessoas jurídicas".

10 LEMES, Selma Ferreira. Arbitragem na administração pública: fundamentos jurídicos e eficiência econômica. São Paulo: Quartier Latin, 2007, p. 125-126.

${ }^{11}$ Ibidem, p. 127-128.
} 
Revista Eletrônica de Direito Processual - REDP.

Rio de Janeiro. Ano 15. Volume 22. Número 2. Maio a Agosto de 2021

Periódico Quadrimestral da Pós-Graduação Stricto Sensu em Direito Processual da UERJ

Patrono: José Carlos Barbosa Moreira (in mem.). ISSN 1982-7636. pp. 166-186

www.redp.uerj.br

A segunda função residiria na exigência da satisfação das necessidades coletivas, o que impulsionaria a Administração a adotar, em cada caso concreto, as melhores soluções possíveis do ponto de vista gerencial, técnico e financeiro, visando conferir maior eficiência e economicidade.

E é justamente sob esta ótica que os mecanismos alternativos, principalmente quando nos referimos à mediação ou conciliação envolvendo a Administração Pública, revelam-se como ferramentas eficazes e capazes de viabilizar uma solução da lide de maneira mais rápida, menos onerosa e mais eficiente, possibilitando-se a filtragem de casos mais simples e de menor valor para que os agentes públicos dediquem maior parte de seu tempo aos casos de maior complexidade, envolvendo vultosas quantias.

\section{INTERESSE PÚBLICO PRIMÁRIO E SECUNDÁRIO - UMA NOVA VISÃo CONCEITUAL SOBRE A DISPONIBILIDADE PARA FINS NEGOCIAIS}

É igualmente de suma importância a classificação do interesse público como primário ou secundário, já que os critérios nela envolvidos servem como elemento norteador da disponibilidade dos bens jurídicos envolvidos nas causas em face da Fazenda Pública.

Uma pergunta que se deve fazer antes de qualquer ponderação consiste na identificação dos objetivos e motivos que circundam a ação do Estado ao desempenhar suas funções política e legislativa. Estando voltados inteiramente à satisfação de um interesse comum pertencente a uma considerável parcela da população podemos afirmar com margem de segurança que estamos diante de um interesse público originário ou primário.

Ou seja, não basta que o ato emanado pelo Estado esteja dentro da esfera do poder legislativo ou de cunho político. Até porque aqui podem estar inseridos atos com evidente desvio de poder, impessoalidade e outros vícios rechaçados pela Constituição que lhes retira a legitimidade sobre seu teor como algo que verdadeiramente externa e representa o interesse público primário.

A topologia do ato emanado da Administração Pública auxilia na detecção de um interesse público primário, mas não faz presunção absoluta sobre isto. Deve-se investigar mais a fundo se as circunstâncias sobre as quais o ato foi concebido ratificam a sua essência como a de um interesse público originário ou primário. 
Revista Eletrônica de Direito Processual - REDP.

Rio de Janeiro. Ano 15. Volume 22. Número 2. Maio a Agosto de 2021

Periódico Quadrimestral da Pós-Graduação Stricto Sensu em Direito Processual da UERJ

Patrono: José Carlos Barbosa Moreira (in mem.). ISSN 1982-7636. pp. 166-186

www.redp.uerj.br

A Administração Pública, por sua vez, ao desempenhar a função administrativa, adota e operacionaliza as diretrizes dos órgãos de governo, atuando especificamente na realização do interesse público derivado ou secundário ${ }^{12}$.

De acordo com a doutrina de Diogo de Figueiredo Moreira Neto, os interesses públicos primários seriam aqueles interesses que se referem às necessidades básicas e primordiais da sociedade. Os interesses secundários seriam, na concepção do autor, os interesses públicos de caráter instrumental, ou seja, aqueles relacionados à operacionalização das atividades finalísticas do Estado, seus atos, contratação de pessoal, serviços e outros casos similares ${ }^{13}$.

A partir de tais considerações, pode-se extrair que o Estado tutela interesses relevantes para a sociedade, mas isto por si só não desautoriza eventual relativização sobre a indisponibilidade - ainda mais quando se esteja diante de situações enquadráveis como ideias a partir de um juízo de conveniência e de oportunidade. Nas atividades estatais reputadas como atividades-meio - portanto, não finalísticas - pode-se falar que o interesse público é derivado, logo, as questões a ele afetas podem ser pacificamente objeto de negociação, dado o seu caráter instrumental e finalidade meramente operacional, limitandose o seu alcance em situações que tenham desdobramentos estritamente patrimoniais ${ }^{14}$.

A jurisprudência consagra a distinção entre o interesse público primário, absolutamente indisponível, e o interesse público secundário, de caráter patrimonial,

\footnotetext{
12 Ibidem, p. 130.

13 MOREIRA NETO, Diogo de Figueiredo. Uma Nova Administração Pública. Revista de Direito Administrativo. V. 220. Rio de Janeiro: FGV Direito Rio, 2000, p. 180-182.

14 LEMES, Selma Ferreira. Arbitragem na administração pública: fundamentos jurídicos e eficiência econômica. São Paulo: Quartier Latin, 2007, p. 130-131. Mas essa indisponibilidade, apesar de ser regra, comporta relativização. A indisponibilidade pressupõe a inegociabilidade, que só pode ocorrer por vias políticas e na forma legal. Mas para executar as atividades-meio", a indisponibilidade é relativa, pode ser negociada e recai sobre os "interesses públicos derivados", para atuar nesta órbita, a Administração demanda autorização constitucional genérica (arts. 18, 37, caput) e, às vezes, autorização legal (por exemplo, arts. 49, I, XVI e XVII da CF). Podemos classificar os interesses públicos em "primários" e "secundários" (instrumentais ou derivados). Os interesses públicos primários são indisponíveis e, por sua vez, os interesses públicos derivados têm natureza instrumental e existem para operacionalizar aqueles, com características patrimoniais e, por isso, são disponíveis e suscetíveis de apreciação arbitral. Esta conclusão, portanto, traz à tona a solução com referência à matéria suscetível de ser submetida à arbitragem: os interesses públicos derivados, de natureza instrumental e com características patrimoniais dispostos em contrato.
} 
Revista Eletrônica de Direito Processual - REDP.

Rio de Janeiro. Ano 15. Volume 22. Número 2. Maio a Agosto de 2021

Periódico Quadrimestral da Pós-Graduação Stricto Sensu em Direito Processual da UERJ

Patrono: José Carlos Barbosa Moreira (in mem.). ISSN 1982-7636. pp. 166-186

www.redp.uerj.br

plenamente disponível pela Administração Pública em conflitos estabelecidos com particulares ${ }^{15}$.

Sob outro ponto de vista, Gustavo Binenbojm destaca que a proteção de um interesse privado em conformidade com os ditames constitucionais, ainda que de forma parcial, representa igualmente a realização de um interesse público ${ }^{16}$.

Tal ponderação se demonstra bastante interessante, pois existe uma forte tendência de se reconhecer um interesse público apenas em situações nas quais o titular do direito seja um ente público. E, a contrario sensu, nem sempre que se está diante de um direito ou bem de titularidade estatal, se está diante de um interesse público.

Marcos Juruena Villela Souto, com base na obra de Diogo de Figueiredo, sustentava que o princípio da Supremacia do Interesse Público restaria desde há muito tempo superado, uma vez que formulado com tamanha abstração e abrangência, confundindo-se com um interesse que seria próprio do ente estatal, por vezes externo e contraposto ao dos administrados, revelando-se, pois, como um instrumento de opressão e arbítrio da autoridade $^{17}$.

Marcella Brandão ao fazer uma análise comparativa da indisponibilidade dos interesses públicos com outros direitos, que, embora sejam indisponíveis por natureza, comportam em algumas situações a transigibilidade sobre um de seus aspectos, traz importantíssima ponderação ao caso em discussão tornando claro que a indisponibilidade não guarda relação direta com negociabilidade. Em outras palavras, um bem ou direito

\footnotetext{
15 Neste sentido, veja-se: RE 303.806 - RO - Relator Ministro Luiz Fux, julgado em 22.03.2005; RESP 490.726 - SC - I Turma, Ministro Relator Teori Albino Zavascki, julgado em 21.03.2005; RESP 28110 - MS - I TURMA, Relator Garcia Vieira, votação unânime; RESP 327.285 - DF, Ministro Relator Ruy Rodado de Aguiar, julgamento unânime em 18.03.2002; RESP 197.586-SP - I TURMA, Min. Relator Garcia Vieira, julgamento unânime em 05.04.1999 e, por fim, MS - 11308 - DF - Relator Min. Luis Fux - 2005/02127630 .

${ }^{16}$ BINENBOJM, Gustavo. Temas de Direito Administrativo e Constitucional. Rio de Janeiro: Renovar, 2008, p. 77. Em vez de uma regra de prevalência, impõe-se ao intérprete/aplicador do direito um percurso ponderativo que, considerando a pluralidade de interesses jurídicos em jogo, proporcione solução capaz de realizá-los ao máximo. E é essa ponderação para atribuir máxima realização aos direitos envolvidos o critério decisivo para a atuação administrativa.

17 SOUTO, Marcos Juruena Villela. Direito Administrativo em Debate. Rio de Janeiro: Lumen Juris, 2004, p. 479. Segundo o autor, no Curso de Direito Administrativo tem-se repetidamente sustentado a obsolescência do então chamado princípio da supremacia do interesse público, que formulado com tal abstração e abrangência, como interesse próprio da pessoa estatal, externo e contraposto aos das pessoas, servia como instrumento de opressão e, de arbítrio da autoridade. Com o advento das constituições instituidoras do Estado Democrático, os valores da pessoa humana foram reentronizados como os que realmente são supremos.
} 
Revista Eletrônica de Direito Processual - REDP.

Rio de Janeiro. Ano 15. Volume 22. Número 2. Maio a Agosto de 2021

Periódico Quadrimestral da Pós-Graduação Stricto Sensu em Direito Processual da UERJ

Patrono: José Carlos Barbosa Moreira (in mem.). ISSN 1982-7636. pp. 166-186

www.redp.uerj.br

mesmo que indisponível por natureza, pode comportar uma negociação envolvendo um aspecto periférico disponível, como por exemplo, repercussões patrimoniais e obrigações de fazer ou de não fazer relacionadas à sua preservação e conservação ${ }^{18}$.

Pelo exposto, resta claro que o interesse público primário é, em sua essência, o real interesse público a ser tutelado, não sendo concebível a preservação de um interesse secundário ou reflexo como um "direito público fazendário" ou da "direito da administração“, logo, absolutamente indisponível, configurando-se assim um verdadeiro obstáculo à realização de um bem comum, de forma célere e eficiente, via mecanismos alternativos em face da Administração Pública.

Fazendo alusão à tendência no ordenamento brasileiro de se distinguirem as hipóteses em que a Administração Pública defende interesses públicos primários, daquelas em que defende interesses públicos secundários, Leonardo Greco conclui que "os chamados privilégios processuais da Fazenda Pública somente se legitimam para suprir eventual inferioridade do Estado em relação ao particular", reforçando a importância de se garantir a paridade de armas no âmbito processual ${ }^{19}$.

Vale fazer referência à doutrina que, de maneira incansável, vem reforçando a necessidade de se interpretar os conceitos e princípios de maneira coerente, não se podendo

\footnotetext{
${ }^{18}$ BRANDÃO, Marcella Araújo da Nova. A consensualidade e a administração pública em juízo. Dissertação apresentada no Mestrado Profissional em Poder Judiciário da Fundação Getúlio Vargas. Rio de Janeiro, 2009. Disponível no site: http://bibliotecadigital.fgv.br/dspace/bitstream/handle/10438/2766/DMPPJ\%202009\%20\%20Marcella\%20Araujo\%20da\%20Nova\%20Brand\%C3\%A3o.pdf?sequence=1\&isAllowed=y. Acesso em: 01 fev. 2019. A autora enfatiza como exemplo a questão dos alimentos, que, a piori, seriam irrenunciáveis. Entretanto, é comum nas varas de família a homologação de acordos sobre os valores dos alimentos, entre outros aspectos periféricos, a demonstrar que indisponibilidade não guarda relação direta com negociabilidade. O mesmo pode se dizer dos valores normalmente protegidos em ações civis públicas, como meio ambiente e patrimônio histórico, indisponíveis e comumente objeto de negociação nos termos de ajustamento de conduta firmados com o Ministério Público Federal. A própria Constituição garante ao Ministério Público a legitimidade para proteger direitos sociais ou individuais indisponíveis, conforme o artigo 127. Assim, mesmo considerando-se existir certa indisponibilidade pela natureza do direito envolvido no conflito judicial, interesses nele contidos podem vir a ser objeto de transação, mesmo que parcial, ao abranger aspectos periféricos do direito material objeto da demanda, como ocorre, por exemplo, nos acordos em ações civis públicas que envolvem impactos no meio ambiente. Certamente a proteção do meio ambiente é indisponível, fato inquestionável. Contudo, a conduta da parte lesiva pode ser ajustada em acordo de modo a evitar a propagação do dano ambiental, por exemplo. Neste ponto, ainda acrescenta a autora que uma conclusão contrária violaria o princípio da igualdade das partes do processo, ao alijar a parte pública da possível conciliação. E tal entendimento superaria ainda a vontade da lei, que, quando quis excluir a transação, o fez expressamente, como verificado no artigo 17 da Lei de Improbidade então vigente.

19 GRECO, Leonardo. A busca da verdade e a paridade de armas na jurisdição administrativa. In: Revista da Faculdade de Direito de Campos, Ano VII, No 9 - Dezembro de 2006, p. 133-140.
} 
Revista Eletrônica de Direito Processual - REDP.

Rio de Janeiro. Ano 15. Volume 22. Número 2. Maio a Agosto de 2021

Periódico Quadrimestral da Pós-Graduação Stricto Sensu em Direito Processual da UERJ

Patrono: José Carlos Barbosa Moreira (in mem.). ISSN 1982-7636. pp. 166-186

www.redp.uerj.br

atribuir a uma suposta indisponibilidade do interesse público um comando de valor absoluto $^{20}$.

Destarte, buscou-se comprovar neste tópico que em momento algum o ordenamento pátrio se encarregou de tornar absolutamente inegociável um interesse público, pelo contrário.

A proteção estatal almejada por tantas vezes, em seguidos atos legislativos até repetitivos por vezes em sua essência, pode estar garantida em algo diferente dos métodos tradicionais de intangibilidade de bens que sequer estão tendo utilizado ou valor de mercado.

Deste modo, exsurgem os mecanismos de negociabilidade como forma de disposição de bens e de interesses públicos, aptos a concretizar na prática os princípios da Administração Pública previstos no art. 37 da Constituição, que, somados a um juízo de conveniência e oportunidade, exigem do Administrador a prolação de uma decisão final consubstanciada em um ato administrativo dotado de fundamentação analítica, resultante de uma profunda e exaustiva análise sobre critérios de economicidade e eficiência ${ }^{21}$.

\section{IDENTIFICAÇÃO DOS BENS E INTERESSES DA ADMINISTRAÇÃO PÚBLICA DISPONÍVEIS E SUJEITOS À MEDIAÇÃo}

Uma vez esclarecido se o interesse público é primário ou secundário, portanto, autorizador ou não sobre a utilização da mediação pela Administração Pública, passa-se a uma nova etapa de discussão caso se decida pela utilização do método alternativo de solução dos conflitos.

Em se tratando de causas envolvendo a Administração Pública e particulares, a adoção da mediação seria apenas justificável nas causas envolvendo bens ou direitos passíveis de disposição, sem que haja prejuízo ou lesão às partes envolvidas.

\footnotetext{
20 LEMES, Selma Ferreira. Arbitragem na administração pública: fundamentos jurídicos e eficiência econômica. São Paulo: Quartier Latin, 2007, p. 124-125.

${ }^{21}$ DAVID, Tiago Bitencourt. Eficiência, economicidade e direitos fundamentais: um diálogo necessário e possível. In: Revista do Ministério Público do Rio Grande do Sul. Porto Alegre, 2010. Disponível em: http://www.amprs.org.br/arquivos/revista_artigo/arquivo_1303929957.pdf. Acesso em 11 mar. 2019.
} 
Revista Eletrônica de Direito Processual - REDP.

Rio de Janeiro. Ano 15. Volume 22. Número 2. Maio a Agosto de 2021

Periódico Quadrimestral da Pós-Graduação Stricto Sensu em Direito Processual da UERJ

Patrono: José Carlos Barbosa Moreira (in mem.). ISSN 1982-7636. pp. 166-186

www.redp.uerj.br

Dentre os direitos absolutamente indisponíveis estão os direitos da personalidade e aqueles relacionados à honra ou estado da pessoa. Normalmente são considerados relativamente disponíveis os direitos patrimoniais.

$\mathrm{Na}$ esfera dos direitos patrimoniais a disponibilidade se faz presente na maior parte dos casos, nos quais se identifica uma tutela de alcance individual, bens passíveis de conversão monetária e que se encontrem desembaraçados, ou seja, de livre disposição por parte de seu titular.

Os direitos patrimoniais indisponíveis a seu turno, seriam aqueles que gerariam algum impacto considerável sobre interesses gerais ${ }^{22}$.

Selma Ferreira Lemes esclarece que a disponibilidade ou indisponibilidade de direitos patrimoniais não tem qualquer relação com a disponibilidade ou indisponibilidade do interesse público. Fazendo referência à doutrina de Eros Roberto Grau, frisa a autora que a disposição de direitos patrimoniais pode estar relacionada ou não à realização de um interesse público ${ }^{23}$.

No caso da mediação envolvendo o ente público deve haver uma conjugação de fatores: existência de interesse público disponível, e, uma vez eleita a via alternativa como aquela mais conveniente, oportuna, que atenda melhor aos critérios de economicidade e eficiência, os bens e direitos objeto de negociação devem possuir alguma conotação patrimonial relativizável, mesmo que de maneira periférica ou reflexa.

Assim, os bens públicos patrimoniais, embora indisponíveis por natureza, são passíveis de transação uma vez que constituem direitos relativamente indisponíveis.

O conceito de disponibilidade pode se relacionar com os conceitos de negociabilidade e de bens suscetíveis de valor e livres no mercado. A relativização da indisponibilidade dos bens públicos pode ser concebida nas relações jurídicas envolvendo o Estado, quando, investido do poder de gestão, contrata com particulares.

Caso semelhante de relativização da indisponibilidade de direitos é observado em sede trabalhista, de onde se extrai a ponderação dos direitos dos trabalhadores, permitindose a realização de conciliações e de acordos coletivos.

\footnotetext{
22 CRETELLA NETO, José. Curso de arbitragem. Rio de Janeiro: Forense, 2004, p. 55-56.

23 LEMES, Selma Ferreira. Arbitragem na administração pública: fundamentos jurídicos e eficiência econômica. São Paulo: Quartier Latin, 2007, p.130.
} 
Revista Eletrônica de Direito Processual - REDP.

Rio de Janeiro. Ano 15. Volume 22. Número 2. Maio a Agosto de 2021

Periódico Quadrimestral da Pós-Graduação Stricto Sensu em Direito Processual da UERJ

Patrono: José Carlos Barbosa Moreira (in mem.). ISSN 1982-7636. pp. 166-186

www.redp.uerj.br

Em trabalho sobre a conciliação judicial e a indisponibilidade dos direitos no direito trabalhista, Elaine Nassif ponderou que o direito patrimonial deve se traduzir no valor quantitativo que o exprime, não sendo apenas um protocolo de intenções. Para a autora, dizer-se que renunciar ao quantitativo não equivale a uma renúncia ao direito, sendo esta inaceitável. Complementa ainda asseverando que a certeza sobre o direito a receber algo somente passa a ser realmente possível após a prolação de uma sentença, ou seja, tudo que ocorre anteriormente à decisão judicial final é res dúbia ${ }^{24}$.

A partir de tal concepção evidencia-se a importância de se distinguir os conceitos de renúncia e transação, uma vez que a indisponibilidade compreende restrições à renúncia e não à transação, na medida em que a primeira é ato jurídico unilateral e a última, ato jurídico bilateral de concessões recíprocas ${ }^{25}$.

Isto significa dizer que a indisponibilidade de bens e direitos (públicos ou privados) só se justifica (logo, se aplica) quando exista algum ato ou negócio jurídico que ameace a sua completa integridade, de modo a ocasionar alguma lesão ou prejuízo aos interesses de uma das pessoas envolvidas, ocasionando-lhe patente desvantagem.

Ademais, os direitos e interesses que seriam indisponíveis, quando discutidos em juízo, recaindo sobre eles uma dúvida capaz de autorizar a sua negociação, desde que haja vantagens para os envolvidos e seja mantida uma situação de equilíbrio em patamares razoáveis.

Pode-se afirmar que sempre existirá para os demandantes a possibilidade de negociação de um direito material classificado como indisponível diante da possibilidade de promover o encerramento daquela questão de maneira mais célere, evitando-se as custas e despesas decorrentes de uma longa tramitação judicial, e, por fim, eliminando-se a incerteza do resultado mediante o acordo celebrado entre as partes envolvidas, resgatando-se precocemente uma situação de equilíbrio e de segurança jurídica.

Ao mencionar segurança jurídica, vale lembrar que parte da doutrina entende que a presença de um juiz togado seria indispensável no momento da celebração de acordos, ainda

\footnotetext{
${ }^{24}$ NASSIF, Elaine. Conciliação judicial e indisponibilidade de direitos: paradoxos da "justiça menor" no processo civil e trabalhista. São Paulo: LTr, 2005, p 214.

${ }^{25}$ Ibidem, p. 215.
} 
Revista Eletrônica de Direito Processual - REDP.

Rio de Janeiro. Ano 15. Volume 22. Número 2. Maio a Agosto de 2021

Periódico Quadrimestral da Pós-Graduação Stricto Sensu em Direito Processual da UERJ

Patrono: José Carlos Barbosa Moreira (in mem.). ISSN 1982-7636. pp. 166-186

www.redp.uerj.br

mais envolvendo direitos e interesses originalmente indisponíveis que foram passíveis de relativização.

Outro questionamento que se coloca no âmbito das arbitragens é a limitação subjetiva, permitindo-se somente que a Administração Pública solucione controvérsias contratuais envolvendo entidades exploradoras de atividade econômica.

Do ponto de vista pragmático, a limitação não deve ser estabelecida tendo-se como parâmetro a natureza do ente que irá transigir com a Administração Pública, pois o que realmente importa é a verificação sobre a disponibilidade ou não do objeto litigioso.

Como muito bem observado por Alexandre dos Santos Aragão, a arbitragem envolvendo a Administração Pública demonstra-se viável em questões contratuais, pois ali reside predominantemente o elemento volitivo como fundamento para as pactuações. Isto significa dizer que seria muito difícil admitir-se a arbitragem envolvendo o Poder Público sobre questões que não possam ser objeto de contratos - ou seja: que possam se originar da manifestação de vontade dos envolvidos. E essa construção termina desvendando a razão de se verificar na prática a arbitragem sendo utilizadas, exclusivamente, por entidades exploradoras de atividade econômicas, com grande destaque para os contratos de concessão em diversos setores relacionados à infraestrutura e outros serviços essenciais ${ }^{26}$.

\subsection{ECONOMICIDADE E EFICIÊNCIA COMO CRITÉRIOS BALIZADORES E DESCONSTRUÇÃO DO PRINCÍPIO DA SUPREMACIA DO INTERESSE PÚBLICO}

Em que pese o fato do presente trabalho ter por objetivo traçar linhas estruturais para a utilização de mecanismos processuais, este ponto embasa-se na melhor doutrina administrativista de Diogo de Figueiredo, que no Congresso Brasileiro de Direito Constitucional ocorrido em São Paulo no ano de 2000, proferiu palestra cujo teor foi consubstanciado em artigo, publicado no Volume 220 da celebrada Revista de Direito

\footnotetext{
${ }^{26}$ ARAGÃO, Alexandre Santos de. A Arbitragem no Direito Administrativo. In Revista da Advocacia-Geral da União. Vol. 16. Brasília, DF: AGU, 2017, p. 19-58.
} 
Revista Eletrônica de Direito Processual - REDP.

Rio de Janeiro. Ano 15. Volume 22. Número 2. Maio a Agosto de 2021

Periódico Quadrimestral da Pós-Graduação Stricto Sensu em Direito Processual da UERJ

Patrono: José Carlos Barbosa Moreira (in mem.). ISSN 1982-7636. pp. 166-186

www.redp.uerj.br

Administrativo da Fundação Getúlio Vargas, considerado como uma das maiores referências em matéria de economicidade e eficiência na Administração Pública ${ }^{27}$.

No primeiro plano, o ilustre administrativista destaca a importância de os administrados terem a oportunidade de participarem ativamente na coisa pública, saindo da antiga posição de súditos e passando à condição de cidadãos. Por meio do exercício desta consciência cidadã, os administrados ao cobrarem um melhor resultado da administração dos interesses públicos, passariam à condição de colaboradores do Estado, exercendo um papel relevante no incremento da eficiência e efetividade estatal.

Por eficiência, entenda-se a qualidade da atividade desempenhada pela Administração Pública capaz de revelar por meio de metas de desempenho e o emprego de técnica de indicadores jurídicos, quantitativos e qualitativos, uma satisfatória proteção dos interesses do cidadão, seja como usuário dos serviços públicos ou como sujeito de outros inúmeros direitos e prestações essenciais garantidas pelo Poder Público ${ }^{28}$.

Para Diogo não bastava o fato da Administração Pública se apresentar eficaz, sendo necessário que também se demonstrasse eficiente. O que ele quis dizer com isto? Ora, o plano da eficácia relaciona-se ao atingimento do resultado, ao passo que a eficiência relaciona-se com todo o caminho percorrido para que ele seja atingido.

Fato é que em diversos casos, um administrado consegue o atendimento ao seu pleito ao final de um processo administrativo (estamos aqui no plano da eficácia); mas se este resultado vier a ocorrer após uma tramitação desorganizada, lenta e excessivamente burocrática, levando o cidadão a sofrer injustamente sucessivos aborrecimentos infundados, podemos afirmar que o Estado foi eficaz, mas não se demonstrou eficiente.

Note-se que a eficiência é uma via de mão dupla, pois sua ausência acarreta prejuízos também para a própria Administração Pública. Seja pela judicialização de questões de resolução simples, seja pelo incremento do gasto público com má gestão de pessoal e de

27 MOREIRA NETO, Diogo de Figueiredo. Uma Nova Administração Pública. Revista de Direito Administrativo. V. 220. Rio de Janeiro: FGV Direito Rio, 2000, p. 180-182.

${ }^{28}$ Ibidem, p. 181. Reproduz-se aqui interessante trecho da palestra, na qual Diogo de Figueiredo afirma que "na mesma linha, o avanço da consensualidade e dos consequentes mecanismos de coordenação - a cooperação e a colaboração - leva à valorização dos resultados da ação administrativa, ou seja, passa-se a considerar que tão importante quanto a administração submissa à legalidade (a busca da eficácia), deve ser a boa administração, fiel à legitimidade (a busca da eficiência), em que definem ambas, tanto a eficácia como a eficiência distintos e covalentes direitos subjetivos públicos do administrado". 
Revista Eletrônica de Direito Processual - REDP.

Rio de Janeiro. Ano 15. Volume 22. Número 2. Maio a Agosto de 2021

Periódico Quadrimestral da Pós-Graduação Stricto Sensu em Direito Processual da UERJ

Patrono: José Carlos Barbosa Moreira (in mem.). ISSN 1982-7636. pp. 166-186

www.redp.uerj.br

recursos e seja pelo desgaste de sua imagem e grau de confiabilidade em relação aos cidadãos.

Assim, Diogo de Figueiredo encerrou notavelmente o seu discurso preconizando uma "Nova Administração", assim entendida como aquela antenada e em perfeita sintonia com as novas instituições - dentre as quais podemos situar os meios alternativos de pacificação de conflitos - capaz de assim desenvolver "uma atitude positiva, em que a crítica científica, necessária e desejada, guarde um sentido construtivo e, se possível criativo"29.

Destarte, não se falaria mais como referência no ultrapassado Estado de Direito, no qual bastava à Administração atuar em conformidade com a legalidade de maneira eficaz, sob a guarda do tão aclamado princípio da supremacia do interesse público.

Restariam, portanto, estabelecidas as bases para uma "nova Administração Pública", completamente fundada nos alicerces do Estado Democrático de Direito, "no qual agregase à legalidade, a legitimidade; à eficácia, a eficiência; e em lugar da supremacia do interesse público, o princípio da supremacia da ordem jurídica"30.

\section{CONSIDERAÇÕES FINAIS}

Diante do panorama apresentado sobre a disponibilidade do objeto, pode-se concluir pela viabilidade e uso da mediação em causas envolvendo a Fazenda Pública mediante a constatação dos seguintes elementos: identificação da presença de um interesse público secundário em sua essência; na fase negocial que a disponibilidade proposta recaia sobre um direito público patrimonial ou que possa ter a sua indisponibilidade prevista em lei relativizada dentro de um contexto fático-jurídico, sempre zelando-se pela estrita observância das garantias processuais e individuais constitucionalmente previstas.

O emprego dos meios alternativos envolvendo órgãos da Administração Pública ganha certo relevo e tratamento peculiar em razão de especiais prerrogativas que cercam os interesses e direitos de titularidade estatal. Isto não impede a sua relativização e muito menos um processo de negociação, mas isto requer uma análise criteriosa e detalhada sobre as

\footnotetext{
${ }^{29}$ Ibidem, p. 182.

${ }^{30}$ Ibidem, p. 182.
} 
Revista Eletrônica de Direito Processual - REDP.

Rio de Janeiro. Ano 15. Volume 22. Número 2. Maio a Agosto de 2021

Periódico Quadrimestral da Pós-Graduação Stricto Sensu em Direito Processual da UERJ

Patrono: José Carlos Barbosa Moreira (in mem.). ISSN 1982-7636. pp. 166-186

www.redp.uerj.br

características do objeto colocado em discussão, de modo que a solução consensualmente obtida se amolde a todas as regras de direito material e processual aplicáveis aos entes públicos.

Assim, para que sejam estabelecidas as bases de um Estado Democrático, necessário se torna proporcionar ao cidadão uma maior participação na gestão da Administração Pública, fiscalizando os serviços públicos prestados e fazendo valer seus direitos quando suas garantias não forem devidamente atendidas.

Destarte, da mesma forma que o Estado é dotado de poder para exigir dos cidadãos o cumprimento escorreito de suas obrigações, o particular também deve ser dotado de prerrogativas e mecanismos legais que possibilitem o devido acesso aos seus direitos e garantias constitucionalmente asseguradas, quando o Poder Público falha em sua gestão.

Do contrário, estar-se-ia estabelecendo uma situação de desigualdade odiosa, sem qualquer propósito ou razão de existência. A Constituição da República de 1988 é clara ao repudiar no caput do art. $5^{\circ}$ qualquer tratamento discriminatório. E neste contexto, também se insere o Estado quando sujeito de uma relação pactuada com um particular.

Por isso, resta defensável, que, em igualdades de condições, deva também a Administração Pública, seja por erro, falha de gestão, ou incompreensão de uma situação específica, que porventura tenha obstado injustificadamente a realização de uma pretensão individual ou coletiva, se utilize de mecanismos conciliatórios menos burocráticos e mais céleres que potencializem uma eficiente pacificação dos conflitos existentes perante seus órgãos internamente (caso das Câmaras de Conciliação e Arbitragem Internas da Administração $\mathrm{Federal}^{31}$ ) bem como com os seus administrados, conferindo-lhes a correção ou o ajuste de um ato administrativo em conformidade com os critérios de economicidade e eficiência.

No momento de eleger qual o método mais adequado para a solução de um conflito, deve o Administrador fazer uma análise prévia sobre as características do litígio, dando preferência ao uso da conciliação para questões de menor complexidade, envolvendo em

${ }^{31}$ BRASIL. ADVOCACIA-GERAL DA UNIÃO. Câmara de Conciliação e Arbitragem da Administração Federal, destaque-se o seu histórico desde a concepção inicial até sua implantação disponível na Cartilha da Advocacia-Geral da União, acessível em: https://www.gov.br/agu/pt-br/composicao/consultoria-geral-dauniao-1/arquivos/CartilhadaCamaradeConciliacaoeArbitragemdaAPF.pdf. Acesso em 12 fev. 2019. 
Revista Eletrônica de Direito Processual - REDP.

Rio de Janeiro. Ano 15. Volume 22. Número 2. Maio a Agosto de 2021

Periódico Quadrimestral da Pós-Graduação Stricto Sensu em Direito Processual da UERJ

Patrono: José Carlos Barbosa Moreira (in mem.). ISSN 1982-7636. pp. 166-186

www.redp.uerj.br

grande parte dos casos direito meramente patrimonial em valores não expressivos; a mediação para discutir assuntos que requeiram a adoção de técnicas especiais de negociação mediante o auxílio de um terceiro imparcial que possa sugerir soluções a partir das informações apresentadas pelas partes, e, por fim, a arbitragem, que embora pareça a um primeiro momento um método mais oneroso, pode se apresentar mais benéfica em causas envolvendo questões contratuais com valores expressivos, que demandem uma maior dinamicidade e rapidez com a manutenção de um alto nível de tecnicismo, por meio da escolha de árbitros com notória expertise sobre as matérias abordadas.

\section{REFERÊNCIAS}

ARAGÃO, Alexandre Santos de. A Arbitragem no Direito Administrativo. In Revista da Advocacia-Geral da União. Vol. 16. Brasília, DF: AGU, 2017.

BANDEIRA DE MELLO, Celso A. Curso de Direito Administrativo. São Paulo: Malheiros, 2007.

BINENBOJM, Gustavo. Temas de Direito Administrativo e Constitucional. Rio de Janeiro: Renovar, 2008.

BRANDÃO, Marcella Araújo da Nova. A consensualidade e a administração pública em juízo. Rio de Janeiro, 2009. Disponível no site: http://virtualbib.fgv.br/dspace/handle/10438/2766. Acesso em: 01 fev. 2019.

BRASIL. ADVOCACIA-GERAL DA UNIÃO. Câmara de Conciliação e Arbitragem da Administração Federal, destaque-se o seu histórico desde a concepção inicial até sua implantação disponível na Cartilha da Advocacia-Geral da União, acessível em: https://www.gov.br/agu/pt-br/composicao/consultoria-geral-da-uniao1/arquivos/CartilhadaCamaradeConciliacaoeArbitragemdaAPF.pdf. Acesso em 12 fev. 2019.

CRETELLA NETO, José. Curso de arbitragem. Rio de Janeiro: Forense, 2004.

DALLARI, Dalmo de Abreu. Elementos de teoria geral do Estado. São Paulo: Saraiva, 2002.

DAVID, Tiago Bitencourt. Eficiência, economicidade e direitos fundamentais: um diálogo necessário e possível. In: Revista do Ministério Público do Rio Grande do Sul. Porto

Alegre, 2010.

Disponível em: 
Revista Eletrônica de Direito Processual - REDP.

Rio de Janeiro. Ano 15. Volume 22. Número 2. Maio a Agosto de 2021

Periódico Quadrimestral da Pós-Graduação Stricto Sensu em Direito Processual da UERJ

Patrono: José Carlos Barbosa Moreira (in mem.). ISSN 1982-7636. pp. 166-186

www.redp.uerj.br

http://www.amprs.org.br/arquivos/revista_artigo/arquivo_1303929957.pdf.

Acesso em 11 mar. 2019.

FISHER, Roger; URY, William; PATTON, Bruce. Como chegar ao sim: como negociar acordos sem fazer concessões. Tradução Ricardo Vasques Vieira. Rio de Janeiro: Solomon Editores, 2014.

GRECO, Leonardo. A busca da verdade e a paridade de armas na jurisdição administrativa. In: Revista da Faculdade de Direito de Campos, Ano VII, No 9 - Dezembro de 2006.

JUSTEN FILHO, Marçal. Conceito de interesse público e a "Personalização" do Direito Administrativo. In Revista Trimestral de Direito Público. Vol. 26. São Paulo: Malheiros, 1999.

IWAKURA, Cristiane Rodrigues. Conciliação na Administração Pública. Dissertação de mestrado apresentada e defendida em 2010 no Programa de Pós-graduação Stricto sensu da UERJ. Orientação: Professor Leonardo Greco. Disponível no site: http://dominiopublico.mec.gov.br/download/teste/arqs/cp148216.pdf. Acesso em: 11 fev. 2019.

LEMES, Selma Ferreira. Arbitragem na administração pública: fundamentos jurídicos e eficiência econômica. São Paulo: Quartier Latin, 2007.

MARTINS, Sérgio Pinto.

MOREIRA NETO, Diogo de Figueiredo. Uma Nova Administração Pública. Revista de Direito Administrativo. V. 220. Rio de Janeiro: FGV Direito Rio, 2000.

NASSIF, Elaine. Conciliação judicial e indisponibilidade de direitos: paradoxos da "justiça menor" no processo civil e trabalhista. São Paulo: LTr, 2005.

OSÓRIO, Fabio Medina. Existe uma supremacia do interesse público sobre o privado no direito administrativo brasileiro? Revista de Direito Administrativo. Vol. 220. Rio de Janeiro: FGV Direito Rio, 2000.

PEREIRA, Hélio do Valle. Manual da Fazenda Pública em Juízo. 2 ed. Rio de Janeiro: Renovar, 2006.

PINHO, Humberto Dalla Bernardina de; MAZZOLA, Marcelo. Manual de Mediação e Arbitragem. São Paulo: Saraiva, 2019. 
Revista Eletrônica de Direito Processual - REDP.

Rio de Janeiro. Ano 15. Volume 22. Número 2. Maio a Agosto de 2021

Periódico Quadrimestral da Pós-Graduação Stricto Sensu em Direito Processual da UERJ

Patrono: José Carlos Barbosa Moreira (in mem.). ISSN 1982-7636. pp. 166-186

www.redp.uerj.br

SOUTO, Marcos Juruena Villela. Direito Administrativo em Debate. Rio de Janeiro:

Lumen Juris, 2004. 